\title{
An unusual cause of chronic diarrhea
}

\section{Goundappa Loganathan • Kandasamy Prabhakaran • Vijay Sadasivam • Mayank Guptha}

Published online: 22 April 2014

(C) Indian Society of Gastroenterology 2014

Gossypiboma or textiloma is a mass formed around a cotton matrix left within the body. They are usually seen following abdominal surgery with varying intervals to presentation and diagnosis. The clinical manifestations are protean, and they may present as pseudotumor, septic collection, or fistulization with or without transmigration and perforation. Presentation with diarrhea is rare. This colonoscopic image (Fig. 1a) is from a 36-year-old mother symptomatic with painful non-bloody chronic diarrhea of 8 months following lower segment Cesarean section. The gossypiboma was firmly adherent to the wall of the sigmoid, associated with pus discharge into the lumen, and the remaining colon was normal. Contrast-enhanced computed tomography of the abdomen (Fig. 1b) reveals a well-defined lowdensity heterogeneous mass with an external high-density contrast-enhancing wall and an internal spongiform pattern containing multiple small air bubbles [1]. The treatment is surgical removal, although endoscopic retrieval of the gauze has also been reported [2].

\section{G. Loganathan $(\bowtie)$}

Department of Gastroenterology, GL Hospital,

26, Kalaimagal Street, Swarnapuri, Salem 636 004, India

e-mail: loganmanoj@gmail.com

\section{K. Prabhakaran}

Department of Gastroenterology, Pranav Hospital, 108/38,

Brindavan Rd, Fairlands, Salem 636 016, India

\section{Sadasivam}

Department of Radiology, S K S Hospital, Opposite New Bus Stand,

Brindavan Road, Fairlands, Salem 636 016, India

\section{Guptha}

Department of Pathology, Christian Medical College,

Vellore 632 004, India
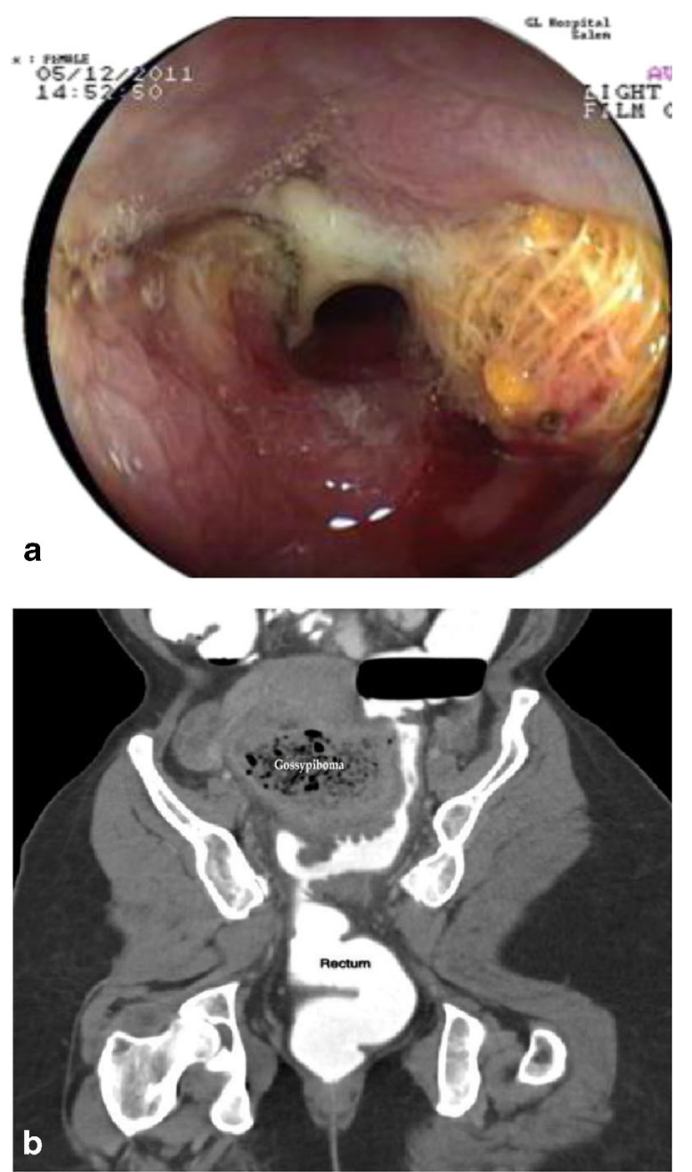

Fig. 1 a Showing colonoscopic view of noodle-like material, pus, and narrowing of sigmoid colon. b Showing coronal reformatted CECT image with a spongiform mass with air pockets, typical of gossypiboma partially infiltrating the lumen of the mid-sigmoid colon on the right side and with pus

\section{References}

1. Manzella A, Filho PB, Albuquerque E, Farias F, Kaercher J. Imaging of gossypibomas: pictorial review. AJR Am J Roentgenol. 2009;193 6 Suppl:S94-S101.

2. Gornals-Soler JB, Lobatón-Ortega T, Rodríguez-Moranta F, MiquelCollell J. Endoscopic retrieval of a surgical gauze from the right colon. Rev Esp Enferm Dig. 2010;102:658-9. 